\title{
PADRÕES DE CRESCIMENTO DOS MUNICÍPIOS E A REPRESENTATIVIDADE INDUSTRIAL EM GOIÁS (2005 A 2015) ${ }^{1}$
}

\author{
GROWTH PATTERNS OF MUNICIPALITIES AND INDUSTRIAL \\ REPRESENTATIVENESS IN GOIÁS (2005 TO 2015)
}

\author{
PATRONES DE CRECIMIENTO DE LOS MUNICIPIOS Y \\ REPRESENTATIVIDAD INDUSTRIAL EN GOIÁS (2005 A 2015) \\ Marcos Fernando Arriel - Secretaria de Desenvolvimento Econômico e \\ Inovação do Estado de Goiás - Goiânia - Goiás - Brasil \\ mfarriel@gmail.com
}

Cintia Neves Godoi - Centro Universitário Alves Faria - Goiânia - Goiás - Brasil

cintia.godoi@unialfa.com.br

\begin{abstract}
Sérgio Duarte de Castro - Pontifícia Universidade Católica de Goiás - Goiânia - Goiás - Brasil sergioucg@gmail.com
\end{abstract}

\section{Resumo}

Os padrões de crescimento dos municípios goianos e as relações existentes com a representatividade de sua atividade industrial no intervalo de tempo de 2005 a 2015 são 0 objeto de análise deste estudo. Pretendese identificar os municípios que formam os aglomerados industriais em Goiás e associar, espacialmente, 0 padrão de crescimento desses municípios e o peso do setor industrial. Dentre os resultados principais, podese destacar que as atividades industriais, especialmente representadas pelas indústrias de transformação e extrativa mineral, proporcionaram ganhos para a expansão da economia goiana e para um conjunto expressivo de municípios. Os resultados também mostraram que o desempenho de um conjunto de municípios foi afetado pela crise econômica brasileira, sobretudo em municípios cujas atividades principais estavam ligadas à commodities minerais, metalmecânica e à produção de medicamentos.

Palavras-chave: Municípios goianos. Indústria de transformação. Indústria extrativa mineral. Padrão de crescimento.

\section{Resumen}

Los patrones de crecimiento de los municipios goianos y las relaciones existentes con la representatividad de su actividad industrial en el intervalo de tiempo de 2005 a 2015 son considerados como el objeto de analize del presente trabajo. Se pretende identificar los municipios que forman los aglomerados industriales en Goiás y asociar, espacialmente, el patrón de crecimiento de estos municipios y el peso del sector industrial. Entre los resultados principales se puede apuntar que actividades industriales, especialmente representadas por industrias de transformación y extractiva mineral, proporcionaron expansión de la economía goiana para un conjunto de municípios. Los resultados también mostraron que el desempeño de un conjunto de municípios fue afectado por la actual crisis económica brasileña, sobre todo en municípios cuyas actividades principales estaban conectadas a los commodities minerales, metalmecánicos y producción de medicamentos. Con estos resultados de la investigación se espera contribuir a un mejor direccionamiento de las políticas públicas de incentivos a la producción industrial.

Palabras clave: Municipios goianos. Industria de transformación. Industria extractiva mineral. Estándar de crecimiento. 


\begin{abstract}
The growth patterns of the municipalities of Goiás State and the relations in the representation of their industrial activity in the period of time from 2005 to 2015 are considered as the aim of analysis in this paper. This work intends to identify the municipalities that form the industrial agglomerations at Goiás State and to associate, spatially, the pattern of growth of these municipalities and the weight of the industrial sector. Among the main results, it can be pointed out that industrial activities, especially represented by the mining and quarrying industries, provided gains for the expansion of Goiás economy and for a significant set of municipalities. The results also showed that the performance of a set of municipalities was affected by the Brazilian economic crisis, especially in municipalities whose main activities were related to mineral commodities, metalworking and the production of medicines. As results of this research, there is an expectation to contribute to a better targeting of public policies for industrial production.

Keywords: Municipalities of Goiás. Transformation industry. Mineral extractive industry. Growth pattern.
\end{abstract}

\title{
Introdução
}

Desde os anos de 1980, Goiás tem passado por importantes transformações na sua estrutura produtiva, o que reverberou na espacialização da renda gerada. Esse fato pode ser creditado, em parte, à indústria, cujo desenvolvimento se deu por meio da integração entre a agropecuária moderna e o avanço da agroindústria, bem como da emergência de novas atividades industriais atraídas pelas políticas de incentivos fiscais, praticadas por Goiás a partir de meados da década de 1980 (Arriel, 2017).

A mudança nas técnicas de produção da agropecuária em Goiás, a partir da década de 1960, preparou as bases para a atração industrial ao estado. À montante da atividade agropecuária, foram atraídos empreendimentos industriais ligados à fabricação de insumos e implementos agrícolas, e à jusante, indústrias ligadas ao complexo de grãos e carnes.

Para Castro e Fonseca (1995), o avanço da agroindústria no CentroOeste e em Goiás se deu em três fases. Na primeira, com o processamento de grãos no processo de adaptação do cultivo de soja na região na década de 1970. A segunda fase se deu pela entrada de tradings no mercado de commodities agrícolas, entre as duas décadas de 1970 e 1980, ligando Goiás com o mercado exterior. Numa terceira fase, a partir da metade da década de 1980, houve o deslocamento dos conglomerados industriais para Goiás de beneficiamento de grãos e de atividades integradoras de criação, abate de aves e de suínos e o processamento de carnes. A integração agropecuária/indústria atraiu segmentos industriais complementares, como embalagens e serviços técnicos de apoio à agropecuária e às agroindústrias. 
Na esteira do processo de integração agropecuária e indústria, Goiás atraiu plantas industriais de fabricação de álcool e açúcar, no final dos anos de 1970 e início dos anos de 1980, beneficiadas pelo Programa de Substituição do Petróleo (PROÁLCOOL). Segundo Estevam (2004), o programa surtiu maior efeito a partir de 1982, e em 1984, 17 indústrias do segmento estavam instaladas em território goiano, sendo duas no norte do estado (hoje estado do Tocantins) e 15 na parte sul.

Afora os segmentos direta ou indiretamente articulados ao agronegócio, se expandem também, nesse período, as indústrias de base mineral, que se beneficiaram dos avanços na logística no estado, e as indústrias tradicionais, que acompanharam o dinamismo econômico e o progresso na urbanização.

Nota-se, ainda, certa diversificação do tecido industrial, com o desenvolvimento de alguns segmentos que não se vinculam com as vantagens comparativas de Goiás, como o farmacêutico, de equipamentos médicos e odontológicos, a automobilística, entre outros segmentos, atraídos pelos incentivos fiscais e financeiros implantados a partir de 1984, com o Fundo de Participação e Fomento à Industrialização do Estado de Goiás (FOMENTAR).

De acordo com Arriel (2017), as transformações ocorridas na indústria em Goiás fizeram com que o setor tivesse ganhos sucessivos na participação da renda estadual. De meados da década de 1980 até o ano de 2014, houve avanços nos três principais indicadores da indústria, Estabelecimentos, Pessoal Ocupado e Valor da Transformação Industrial (VTI). O autor assinala que o VTI foi multiplicado por 3,5 vezes, em relação à participação nacional, tendo seu auge em 2009, e que a expansão da indústria de transformação e extrativa mineral foi fundamental para o efeito dinamizador em outras atividades produtivas e, como reflexo, houve expansão do PIB goiano de maneira superior ao nacional.

Estudos como Arriel $(2010,2017)$ mostram que a atividade industrial, com sua capacidade impulsionadora de outras atividades produtivas, foi determinante para a expansão econômica de Goiás, mas é importante observar como se deu essa dinâmica industrial nos municípios.

\section{Revisão Bibliográfica}

Estudos sobre aglomeração produtiva ganham importância inicialmente com o trabalho pioneiro de Alfred Marshall, no qual se 
destacam as externalidades obtidas pelas empresas inglesas com a aglomeração industrial. Segundo Marshall (1982), a proximidade entre empresas da mesma indústria ou cadeia produtiva atrai mão de obra e fornecedores especializados, favorece a troca de informações e o aprofundamento da divisão do trabalho, contribuindo para o ganho de eficiência e competitividade das empresas. Assim, na visão marshalliana, as forças que alimentam a aglomeração decorrem, sobretudo, da especialização produtiva local.

Jacobs (1969) destaca outro tipo de ganhos de aglomeração, as "economias urbanas". A infraestrutura, a ampla oferta de serviços e a demanda concentrada, bem como o ambiente propício aos encontros e à troca de informações nas cidades representam externalidades importantes para as empresas. Essas tendem a se ampliar com o porte das cidades e com a ampliação de seu leque de atividades econômicas. Segundo Jacobs (1969), cada atividade diferente no ambiente urbano potencializa aquelas externalidades, produzindo um ambiente altamente favorável à criatividade e à inovação. Dessa forma, para a autora, a principal fonte de economias de aglomerações é a diversidade e não a especialização.

No Brasil, até a década de 1970, a indústria brasileira passava por um processo de concentração produtiva que convergia no sudeste brasileiro, sobretudo em São Paulo. A partir de então, segundo Diniz e Crocco (1996), aos poucos passa a se ter movimentos de desconcentração espacial que ocorreu em duas fases. A primeira, promovida em grande parte pelas ações do Estado, entre os anos de 1960 até início da década de 1980, a outra a partir de meados dos anos de 1980, com as políticas estaduais de incentivos fiscais e o movimento de localização das indústrias nas proximidades da produção de matéria-prima.

Nesse processo de implantação de políticas estaduais de incentivos fiscais, Goiás instituiu em 1984 sua primeira política industrial de forma organizada e, aliada à integração produtiva industrial com a base local, agropecuária e mineração, elevou a participação do setor industrial na geração da renda estadual. Segundo Arriel (2010, 2017), a integração da agropecuária e extrativa mineral, com a indústria de transformação e seus desdobramentos, além de promover forte expansão da indústria goiana, também modifica a geografia da produção industrial, que consolidou um conjunto de polos industriais. 
Castro e Arriel (2016) afirmam que, por questões locacionais, as indústrias processadoras dos produtos agropecuários e aquelas de base mineral tenderam a se localizar nas proximidades de suas fontes de matéria prima, e se alimentar de externalidades de especialização, enquanto as indústrias tradicionais, ou aquelas não ligadas às vantagens comparativas de Goiás, foram se aglomerando em Anápolis e na Região Metropolitana de Goiânia.

Embora os estudos de Arriel $(2010,2017)$ tenham apontado um conjunto de municípios polos industriais, não foi possível identificar os aglomerados industriais e nem a contribuição daquela atividade para o processo de crescimento dos municípios goianos. Assim, é importante que se faça a identificação dos aglomerados industriais e verificar se nesses municípios a atividade industrial foi decisiva para a expansão da economia local.

Para o estado do Paraná, Santos et al. (2017) identificou o padrão de crescimento e os aglomerados industriais com base em metodologia definida por Piacenti (2009), no intuito de contribuir para o conhecimento territorial, chamando atenção para a concentração espacial da atividade industrial e sua capacidade em contribuir para a expansão econômica dos municípios. O estudo dos referidos autores lança mão do Quociente Locacional (QL), medida tradicionalmente utilizada na literatura da economia regional, combinado com o Índice do Nível de Crescimento Econômico (INC) e com o Índice do Ritmo de Crescimento Econômico (IRC). Santos et al. (2017) constataram que a indústria de transformação do Paraná apresentou significativo crescimento entre os anos de 2005 a 2010, mas espacialmente continuou concentrada em pontos específicos do estado, ainda que aquela atividade tenha desconcentrado no estado.

\section{Metodologia}

Para analisar a importância da indústria para o crescimento econômico dos municípios goianos, demonstrando os aglomerados industriais e associando aos padrões de crescimento desses municípios, entre os de 2005 e 2015, adaptou-se a metodologia desenvolvida por Santos et al. (2017) para o estado do Paraná, baseado em Piacenti (2009). Para a identificação dos aglomerados industriais em Goiás, utilizou-se o Quociente Locacional (QL), medida tradicionalmente utilizada na 
literatura, que, para Haddad (1989), contribui para a identificação de especialização de determinada atividade produtiva. Na identificação do padrão de crescimento dos municípios goianos, utilizou-se o Índice do Nível de Crescimento Econômico (INC) e o Índice do Ritmo de Crescimento Econômico (IRC), desenvolvidos por Piacenti (2009).

A base de dados utilizada para o cálculo do QL foi a Relação Anual de Informações Sociais (RAIS), do Ministério do Trabalho, referente ao ano de 2015. A RAIS foi instituída pelo Decreto n. ${ }^{\circ}$ 76.900, de 2 dezembro de 1975 (Brasil, 1975), com os objetivos de servir de base de cálculos das quotas do PIS e do PASEP, subsidiar o controle relativo ao FGTS e à Previdência Social, controlar a racionalização do trabalho e viabilizar o pagamento do Abono Salarial, mas é utilizada com frequência como uma importante fonte de registros administrativos em trabalhos que exploram o emprego formal, por apresentar cobertura de quase totalidade dos vínculos formais de trabalho. Para a presente pesquisa, foram extraídos os dados por município, referente ao ano de 2015, e a seções B (Indústrias Extrativas) e C (Indústrias de Transformação) da Classificação Nacional de Atividades Econômicas (CNAE).

$\mathrm{O}$ QL é um índice sintético que permite mostrar em qual setor produtivo o município se destaca ou se diferencia dentre os demais no estado. E ainda, se o município forma uma concentração de empregos dentro de uma mesma atividade econômica muito acima da média registrada para o estado. Um alto QL indica que determinada atividade produtiva possui certa especialização dentro da estrutura produtiva de um município. O QL, portanto, mostra se um determinado município é concentrador de empregos de determinada atividade produtiva, no caso na indústria extrativa mineral ou de transformação. Em termos algébricos, tem-se:

$$
\mathrm{QL}=\frac{\mathrm{Eij}_{\mathrm{j}} / \mathrm{Ei}}{\mathrm{E}_{\mathrm{j}} \mathrm{j} / \mathrm{E}-}
$$

Eij = emprego no setor i, do município j;

E.j = emprego em todos os setores do município;

j; Ei. = emprego no setor i de todos os municípios;

E.. = emprego em todos os setores nos municípios goianos. 
Com base em Haddad (1989), se o resultado do QL for maior do que 1, significa que o setor produtivo $i$ no município $j$ é mais elevado que a participação relativa da média estadual, o que revela, portanto, certa especialização do setor $i$ no município em relação a sua estrutura produtiva.

De posse dos resultados da definição dos padrões de crescimento dos municípios goianos, e da especialização industrial em Goiás, representada pelo $Q L$, foi feito um cruzamento para verificar se os municípios que possuem a indústria como atividade representativa obtiveram padrões de crescimento superiores.

Os índices INC e ICR foram construídos a partir do Produto Interno Bruto (PIB) per capita, que tem como recorte espacial os municípios. Esse indicador é uma referência em relação à capacidade que uma população de uma região tem em absorver mais produção ao longo do tempo.

O PIB dos municípios é calculado pelo IBGE e pelos os órgãos estaduais de estatísticas, através de parceira, obedecendo a metodologia uniforme para todas as Unidades da Federação, e é integrado, conceitualmente, aos procedimentos adotados nos Sistemas de Contas Nacionais e Regionais do Brasil. A estimativa do PIB dos municípios goianos ocorre por meio da apuração do Valor Adicionado Bruto das atividades econômicas dos 246 municípios do estado. Para se chegar ao PIB per capita, basta dividir o PIB pelo número de habitantes de cada município.

De posse do PIB per capita, o cálculo do INC para os municípios goianos foi construído verificando o comportamento de cada município em relação ao PIB per capita médio estadual, conforme a equação a seguir:

$$
\mathrm{INC}=\left(\frac{\mathrm{PIB} \text { pci }}{\mathrm{PIB} \mathrm{pcm}}\right) \times 100
$$

PIBpci = PIB per capita do município $i$ em 2015;

PIBpcm = PIB per capita estadual em 2015. 
Para Piacenti (2009) e Santos et al. (2017), tal procedimento possibilita caracterizar os municípios em relação ao potencial de crescimento, comparando se estão em linha com a média estadual, abaixo, ou com alto potencial de crescimento.

Também utilizando PIB per capita, mas numa perspectiva da dinâmica dos municípios num período de 10 anos, foi calculado o IRC, para a verificação do ritmo da expansão econômica. Com base na equação a seguir, chega-se ao resultado da classificação dos municípios goianos segundo seu ritmo ou padrão de crescimento, sendo caracterizado como: depressivo, recessivo ou estagnado, conforme a definição de Piacenti (2009).

$$
\operatorname{IRC}=\frac{\left[\left(\frac{\pi}{\psi}\right)-1\right]}{\left[\left(\frac{\mathrm{K}}{\Phi}\right)-1\right]_{\mathrm{X}}} 100
$$

$\pi=$ PIBpc2000i $=$ PIB per capita do município i em 2005;

$\psi=$ PItBpc2010i $=$ PIB per capita do município i em 2015;

$\mathrm{K}=\mathrm{PIBp} c 2000 \mathrm{~m}=\mathrm{PIB}$ per capita estadual em 2005;

$\Phi=$ PIBpc $2010 m=$ PIB per capita estadual em 2015.

Após o cálculo dos índices INC e IRC, é realizado o cruzamento do resultado para cada um dos 246 municípios goianos, com o objetivo de identificar o nível de crescimento e o ritmo de crescimento econômico, classificando-os entre acima (A) ou abaixo da média estadual (B), conforme Quadro 1, obedecendo os critérios definidos por Piacenti (2009) e Santos et al. (2017).

Quadro 1 - Combinação dos indicadores municipais Nível de Crescimento (INC) e Ritmo de Crescimento Econômico (IRC)

\begin{tabular}{|l|c|c|c|}
\hline Classificação do município & INC & ICR & Tipo \\
\hline Crescimento em expansão & Alto & Alto & AA \\
\hline Crescimento em declínio & Alto & Baixo & AB \\
\hline Em crescimento & Baixo & Alto & BA \\
\hline Deprimidos & Baixo & Baixo & BB \\
\hline
\end{tabular}

Fonte: Adaptado de Piacenti (2009) e Santos et al. (2017). 
A combinação de municípios com INC e IRC acima da média do estadual, é chamada de Crescimento em expansão (AA); municípios com um INC acima da média estadual, mas com IRC abaixo da média, recebem a classificação de Crescimento em declínio (AB); aqueles municípios com INC abaixo da média do estado e ICR acima da média, são caracterizados como Em crescimento (BA); por último, municípios que expressam um INC e um IRC abaixo da média estadual são denominados de Deprimidos (BB).

\section{Resultados}

\section{Configuração setorial e espacial do emprego industrial em Goiás}

A atividade industrial é composta pela indústria extrativa mineral, de transformação, geração, transmissão, distribuição e comercialização de energia elétrica e construção. Essas atividades somaram, em 2015, ano de observação da presente pesquisa, R $\$ 37,8$ bilhões de Valor Adicionado na economia de Goiás, o que significa $22,9 \%$ do PIB estadual. A indústria de transformação e a extrativa mineral, atividades produtivas desse trabalho, representavam naquele ano 51\% da indústria total e 12,5\% do PIB goiano, mas sua representação do produto foi mais representativa, de 17,1\% em 2009.

A tendência de expansão que vinha se verificando na indústria de transformação e extrativa mineral até 2009, foi quebrada pela crise internacional, refletindo a queda nos preços das commodities minerais, e, posteriormente, de 2013 em diante, com a redução na produção das indústrias do segmento metalmecânico, sobretudo na montagem de veículos, e na produção de medicamentos, afetadas pela elevação do dólar e pela crise interna brasileira.

Os dados da Figura 1, a seguir, mostram que a indústria goiana possui peso significativo de segmentos intensivos em recursos naturais, sendo que a agroindústria, em que se destacam os complexos de processamento de grãos e carnes, o lácteo, o de processamento de tomate e o sucroenergético, é a mais representativa.

Esses segmentos industriais são representados pelo conjunto da indústria de alimentos e bebidas e fabricação de álcool, que, em 2015, representavam mais de 60\% do Valor da Transformação Industrial (VTI) da indústria goiana. 
Figura 1 - Goiás: Estrutura produtiva, em percentual do PIB, da Indústria de Transformação e Extrativa Mineral - 2015

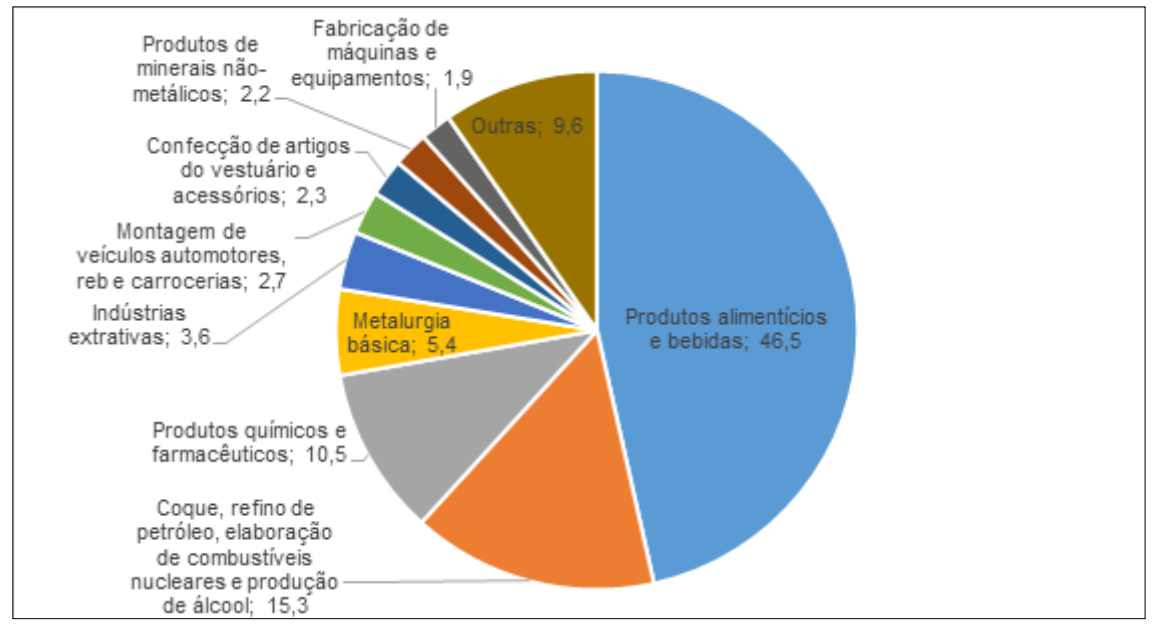

Fonte: Elaboração dos autores a partir de IMB (2017).

Espacialmente, conforme Arriel (2017), a indústria concentra 62,3\% das saídas de mercadorias em apenas dez municípios goianos. A atividade industrial tende a concentrar em busca das vantagens aglomerativas, sejam urbanas ou de especialização, como o mercado, mão de obra, os serviços relacionados, dentre outros, e assim melhorar sua competitividade. Desse modo, a produção industrial se concentrou nos municípios mais populosos e com maior capacidade de geração de serviços, como Anápolis, Rio Verde, Goiânia, Catalão e Aparecida de Goiânia.

Nos segmentos industriais ligados à indústria alimentícia, podem-se destacar a fabricação de óleos vegetais, carnes, laticínios, fabricação de rações e a fabricação de molhos e temperos. Segundo Arriel (2017), as principais indústrias desse segmento estavam localizadas nos municípios de Goiânia, Itumbiara, Jataí, Luziânia, Anápolis, Mineiros e Rio Verde.

Os segmentos produtivos ligados ao processamento de óleos vegetais e fabricação de rações são representativos na indústria alimentícia e estão enraizados no território goiano, localizados em municípios da mesorregião Sul de Goiás. Dados da Associação Brasileira das Indústrias de Óleos Vegetais (ABIOVE) mostram que Goiás possuía, em 2016, uma capacidade de processamento de óleos vegetais de 27,3 mil ton/dia, tendo 
possibilidade de processar mais de $70 \%$ da produção de soja em Goiás. Embora a capacidade de processamento tenha se elevado substancialmente nos últimos anos, o setor industrial vem sofrendo elevada concorrência da China, que elevou a demanda por soja em grão (IMB, 2017).

No complexo de carnes, que envolve o abate de bovinos, aves, suínos e fabricação de produtos de carnes, existem grandes aglomerações em Goiás que estão bastante integradas com a cadeia de grãos, localizando-se principalmente na mesorregião Sul de Goiás e em municípios como Senador Canedo, Mozarlândia e Itaberaí. A demanda de insumos desse segmento encontra-se atendida, em grande medida, localmente. Esse segmento agrega pouco valor, pois há elevado nível de venda de carnes in natura, principalmente para o exterior (ARRIEL, 2017).

No encadeamento produtivo do segmento industrial de laticínios, que compreende a preparação do leite, a fabricação de laticínios e a fabricação de sorvetes, os dados mostram que há elevado relacionamento comercial dentro do estado e Unidades da Federação próximas, caraterísticas do próprio segmento industrial. Sua localização está disseminada no estado, mas Goiânia, Bela Vista de Goiás e Morrinhos se destacam.

A atividade industrial sucroenergética, aqui definida pela junção entre os segmentos da fabricação de açúcar e álcool, tem grande representatividade na geração de renda no estado, totalizando $21,3 \%$ da agregação de valor da indústria de transformação goiana. Os principais municípios que localizam plantas industriais do segmento sucroenergético são Turvelândia, Inhumas, Anicuns, Itapaci e Carmo do Rio Verde. Esse segmento industrial teve início, no estado, no final dos anos de 1970 e início dos anos de 1980. O etanol era visto no país como uma saída ao crescente preço do petróleo no mercado internacional, sendo praticamente esquecido por mais de uma década (ARRIEL, 2017).

Por muitos anos, poucas indústrias desse ramo operaram em Goiás, mas, a partir de 2006, graças à crescente demanda pelo etanol no mercado nacional e internacional, o número de indústrias atingiu $36 \mathrm{em}$ funcionamento. No ano de 2017, a produção goiana de açúcar e álcool do estado ficou na $4^{\mathrm{a}}$ e $2^{\mathrm{a}}$ posição nacional, respectivamente (IMB, 2018). É uma atividade que possui forte integração interna, em função da entrada e saídas de mercadorias. Cabe destacar que a ampliação da capacidade de processamento desse segmento, atraiu indústria de fabricação de colheitadeiras de cana de açúcar para o estado, tendo sua planta industrial ampliada em anos recentes. 
Após essa análise qualitativa mais geral, passou-se ao cálculo do Quociente Locacional (QL) para os 246 municípios goianos, o que permitiu quantificar a importância relativa do emprego industrial na estrutura produtiva em cada município, quando considerado o parâmetro estadual.

Conforme pode ser observado na Tabela 1, a seguir, em 150 dos 246 municípios goianos (61\%) o QL é inferior a 1, o que indica que, na estrutura produtiva municipal, a atividade industrial possui menos representatividade que na média do estado. Para os demais 96 municípios (39\%), apurou-se o QL acima de 1, significando que o emprego industrial desse conjunto de municípios possui representação superior à média, indicando certa especialização da atividade industrial na estrutura produtiva.

Tabela 1 - Distribuição dos municípios goianos, segundo Quociente Locacional (OL) da atividade industrial - 2015

\begin{tabular}{|l|c|c|}
\hline Faixas do Quociente Locacional (0L) & Número de municípios & \% de municípios \\
\hline Abaixo de 1 & 150 & 61,0 \\
\hline de 1 até 2 & 52 & 21,1 \\
\hline de 2 até 3 & 34 & 13,8 \\
\hline de 3 até 4 & 8 & 3,3 \\
\hline Acima de 4 & 2 & 0,8 \\
\hline Total & $\mathbf{2 4 6}$ & $\mathbf{1 0 0 , 0}$ \\
\hline
\end{tabular}

Fonte: Elaboração dos autores a partir de dados da RAIS 2015 (Brasil, 2015).

Quando observado espacialmente, nota-se a concentração espacial das atividades industriais. Entretanto, o QL possui uma limitação pela tendência de se elevar em economias muito pequenas e pouco diferenciadas. Por essa razão, é aconselhável considerar, complementarmente, o número de empresas e/ou o número de trabalhadores total na indústria dos municípios analisados (CASTRO, 2004). Embora o QL seja superior a 1 em 39\% dos municípios goianos, o que indica certa representatividade da atividade industrial no município, ao observar os números de empresas e empregos, nota-se a concentração nos principais polos industriais já relatados anteriormente: Anápolis, Rio Verde, Goiânia, Catalão e Aparecida de Goiânia (Figura 2). 
Figura 2 - Distribuição espacial dos municípios, segundo Quociente Locacional (QL), número de empresas e emprego da atividade industrial - 2015

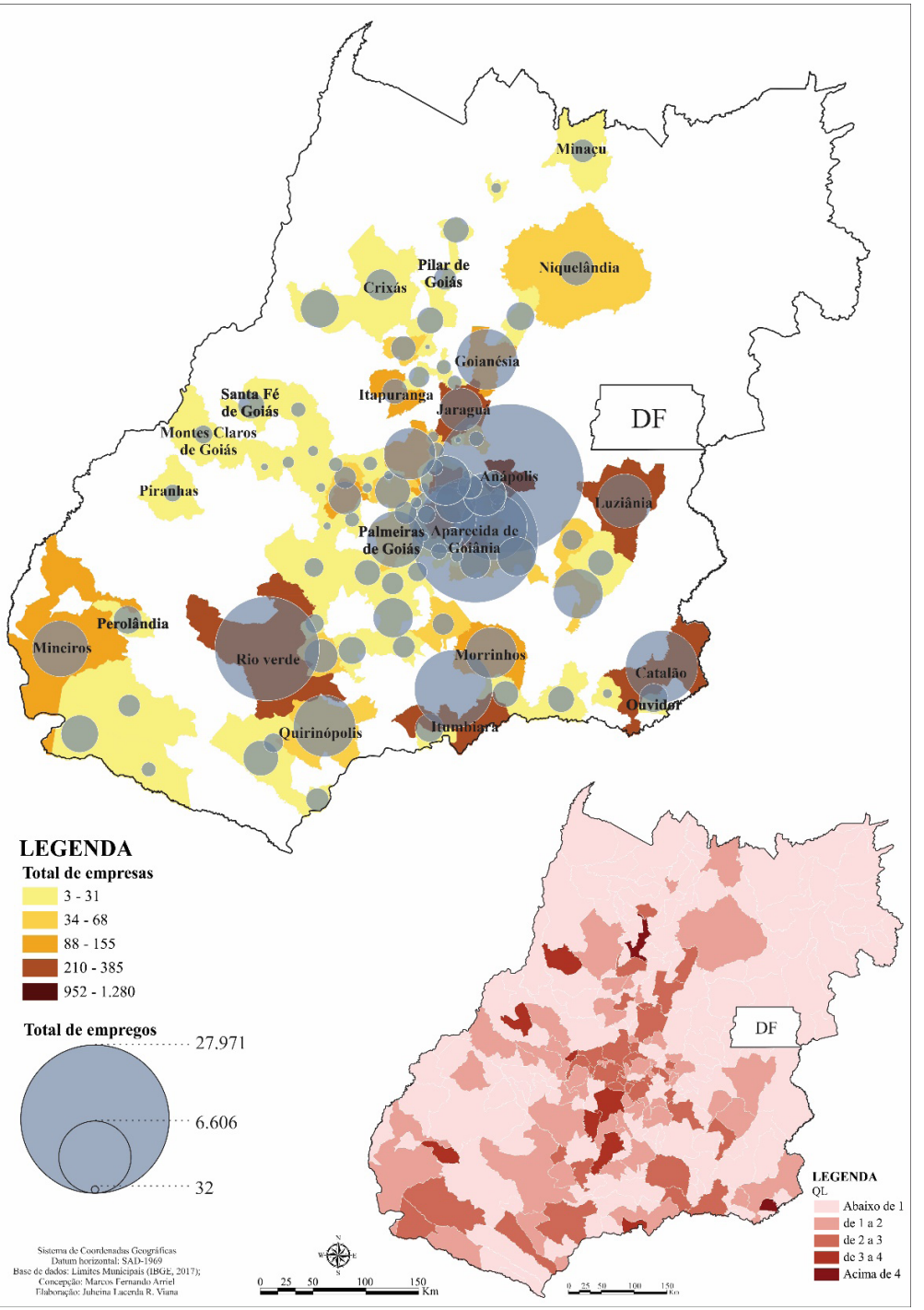

Fonte: Elaboração dos autores a partir de dados da RAIS 2015 (Brasil, 2015). 


\section{Crescimento Econômico e Localização Industrial}

O PIB de Goiás em 2015 era de R\$ 173,632 bilhões, com participação de $2,9 \%$ na economia nacional, o que representa a $9^{\mathrm{a}}$ economia do país, segundo dados do IBGE. Sua estrutura produtiva segue o perfil da economia nacional e das economias contemporâneas, com setor de serviços representando $65,1 \%$ da economia estadual, seguido pela indústria $(24,5 \%)$ e agropecuária (10,4\%). O PIB per capita (PIBpc), relação entre o PIB e a população residente, era de $\mathrm{R} \$ 26.265,32$, representando $89,6 \%$ do PIB per capita nacional.

Para se analisar a relação entre o crescimento econômico e a presença da indústria nos municípios, será feita, inicialmente, uma comparação entre o Índice do Nível de Crescimento econômico (INC) dos municípios com o seu QL industrial. Trata-se de uma etapa estática da análise, que possibilita apreender o resultado passado do desenvolvimento dos municípios a partir do estágio de crescimento em que se encontram hoje, relacionando esse estágio à presença maior ou menor da indústria. As estatísticas permitem inferir a importância da indústria para o resultado alcançado até então.

Dos 246 municípios goianos, apenas 69, 28,0\% do total, possuem INC superior a 100, isto é, contam com PIBpc acima da média do PIBpc do estado (INC A). Desses, 51 municípios apresentaram QL superior a 1, o que significa dizer que 73,9\% dos municípios com INC A, quase dois terços do total, apresentam concentração industrial acima da média estadual. Os resultados permitem concluir que a presença da indústria teve, histórica e estruturalmente, um papel muito importante no desenvolvimento dos municípios goianos.

Em seguida, compara-se o Índice do Ritmo do Crescimento econômico (IRC), referente ao período 2005 e 2015, com o QL dos municípios. Trata-se, nesse caso, de uma análise dinâmica e conjuntural que procura verificar em que medida a maior ou menor presença da indústria contribui com o ritmo de crescimento econômico dos municípios no período considerado. É preciso registrar, contudo, que 2005-2015 é um período marcado pelo impacto da crise mundial de 2008 sobre a economia brasileira e goiana, o que exige qualificações importantes na análise. A crise afetou mais duramente a indústria que a agricultura. Além disso, no âmbito da própria indústria, foi menos prejudicial aos 
setores ligados ao processamento de produtos naturais, cujos preços do mercado internacional se mantiveram, inicialmente, em função da demanda chinesa e, posteriormente, com a valorização do dólar.

Na comparação do IRC com o QL, verifica-se que 135, dos 246 municípios goianos, revelam um IRC superior a 100, o que significa dizer que a taxa de crescimento de seu PIBpc entre 2005 e 2015 foi maior que a média estadual. Esse número representa 54,9\% dos municípios goianos. Contudo, apenas 37 dos 135 municípios com IRC elevado, isto é, 27,4\% do total, apresentaram QL superior a 1. O resultado pode indicar, claramente, que não foi a presença da indústria a responsável pela explicação do desempenho superior daqueles municípios. Há de se ressaltar que a crise econômica afetou muito mais os municípios industriais que aqueles com atividade da agropecuária.

O cruzamento entre os dois indicadores (INC e ICR) permite a classificação dos municípios quanto ao seu nível e ritmo de crescimento em quatro grandes grupos: Crescimento em expansão (AA); Crescimento em declínio (AB); Em crescimento (BA); e Deprimidos (BB). Do total dos 246 municípios goianos, 39 (15,9\%) foram classificados em AA, ou seja, além de ter PIB per capita superior à média estadual, também obtiveram expansão do PIB per capita, no período de 2005 a 2015, superior ao verificado para o estado como um todo. Um conjunto de $30(12,2 \%)$ municípios foi classificado como Crescimento em declínio (AB), ou seja, aqueles que obtiveram um desempenho acima da média estadual no INC e um desempenho abaixo da média no IRC. Outros 96 municípios (39\%) foram classificados como BA, quando possuíam INC abaixo da média estadual, mas obtiveram desempenho acima da média no período de 2005 a 2015. Por fim, 81 municípios (32,9\%) foram classificados como Deprimidos, quando apresentaram desempenho abaixo da média do estado em ambos os índices. 
Tabela 2 - Classificação dos municípios goianos, segundo seu padrão de crescimento a partir da combinação do INC e IRC

\begin{tabular}{l|c|c|c}
\hline Classificação do município & Tipo & Número de municípios & \% de municípios \\
\hline Crescimento em expansão & AA & 39 & 15,9 \\
\hline Crescimento em declínio & AB & 30 & 12,2 \\
\hline Em crescimento & BA & 96 & 39,0 \\
\hline Deprimidos & BB & 81 & 32,9 \\
\hline Total & & $\mathbf{2 4 6}$ & $\mathbf{1 0 0 , 0}$ \\
\hline
\end{tabular}

Fonte: Elaboração dos autores a partir de Piacenti (2009) e Santos et al. (2017).

Conforme Figura 3, nota-se maior concentração dos municípios classificados como AA e AB no centro-sul do estado. Trata-se do conjunto de municípios mais industrializados sendo, estruturalmente, os centros mais dinâmicos do estado. O mapa mostra, contudo, que a crise afetou desigualmente esses municípios levando alguns a terem desempenho abaixo da média no período. Economias como a de Goiânia e Anápolis, com a indústria mais diversificada e presença importante da indústria metalomecânica e farmacêutica, além de um forte setor de serviços, estão nesse grupo. Economias baseadas na extração e transformação mineral como as de Niquelândia e Ouvidor foram bastante afetadas ${ }^{2}$.

Em geral, as economias industriais de base agropecuária conseguiram resistir melhor e crescer, beneficiadas pelo câmbio. O mapa, entretanto, evidencia algumas exceções importantes como os casos de Itumbiara, Goiatuba, Ipameri, Serranópolis, Turvelândia e, mesmo, Rio Verde, que aparecem com classificação AB, com crescimento abaixo da média. O baixo crescimento deve-se, principalmente, ao peso das atividades sucroalcooleiras nesses municípios. Esse tipo de atividade já vinha sofrendo com os subsídios à gasolina do governo federal e foi fortemente abalado pela redução drástica dos preços do petróleo a partir de 2011, e da superoferta de açúcar no mercado internacional. No caso de Rio Verde, onde o setor sucroalcooleiro também é importante, mas com peso relativo muito menor, os efeitos da crise, em sua significativa economia de serviços, ajudam a entender o baixo crescimento. 
Figura 3 - Distribuição espacial dos municípios, segundo seu padrão de crescimento a partir da combinação do INC e IRC

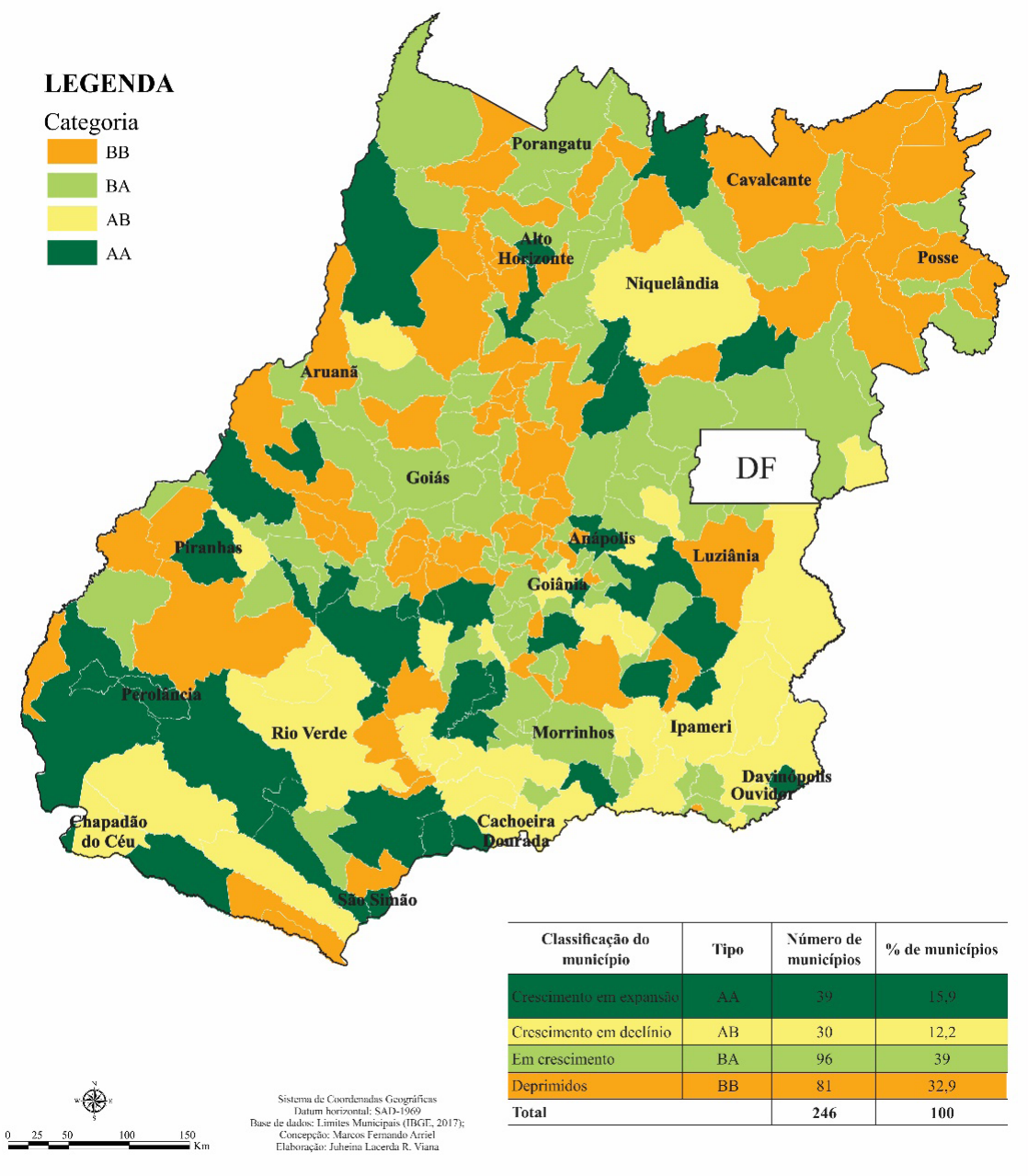

Fonte: Elaboração dos autores a partir de Piacenti (2009) e Santos et al. (2017).

Por outro lado, o bom desempenho da agropecuária durante a crise explica o grande número de municípios (96) classificados como Em crescimento (BA). São municípios com baixa presença industrial mas com 
agropecuária moderna em expansão, favorecida pela desvalorização do real e pela queda dos preços do petróleo.

A situação mais preocupante é a dos municípios Deprimidos, classificados como BB (81), que é o caso de $32,9 \%$ das cidades goianas. Concentram-se, sobretudo, no extremo nordeste e no centro noroeste do estado, regiões que não possuem vantagens locacionais nem para a industrialização nem para a agricultura moderna. São municípios que possuem baixa densidade populacional e elevada dependência de transferências do setor público, como as constitucionais.

Os segmentos industriais ligados à transformação de produtos da agropecuária, como a alimentícia e a sucroenergética, foram o que menos sofreram com a crise, e que, portanto, contribuíram para elevar o padrão de crescimento dos municípios que as abrigam. Por outro lado, os segmentos industriais ligados à indústria metalmecânica, farmacêutica e de extração e transformação mineral, foram os que mais sofreram.

Ao associar o padrão de crescimento dos municípios goianos, combinação do INC e ICR, com a especialização do emprego industrial, através do QL, buscou-se observar o nível de crescimento dos municípios e sua relação com aqueles em que possuem maior especialidade industrial (Figura 4). 
Figura 4 - Distribuição espacial dos municípios, segundo a combinação do padrão de crescimento dos municípios goianos, com especialização do emprego industrial a partir Quociente Locacional (OL)

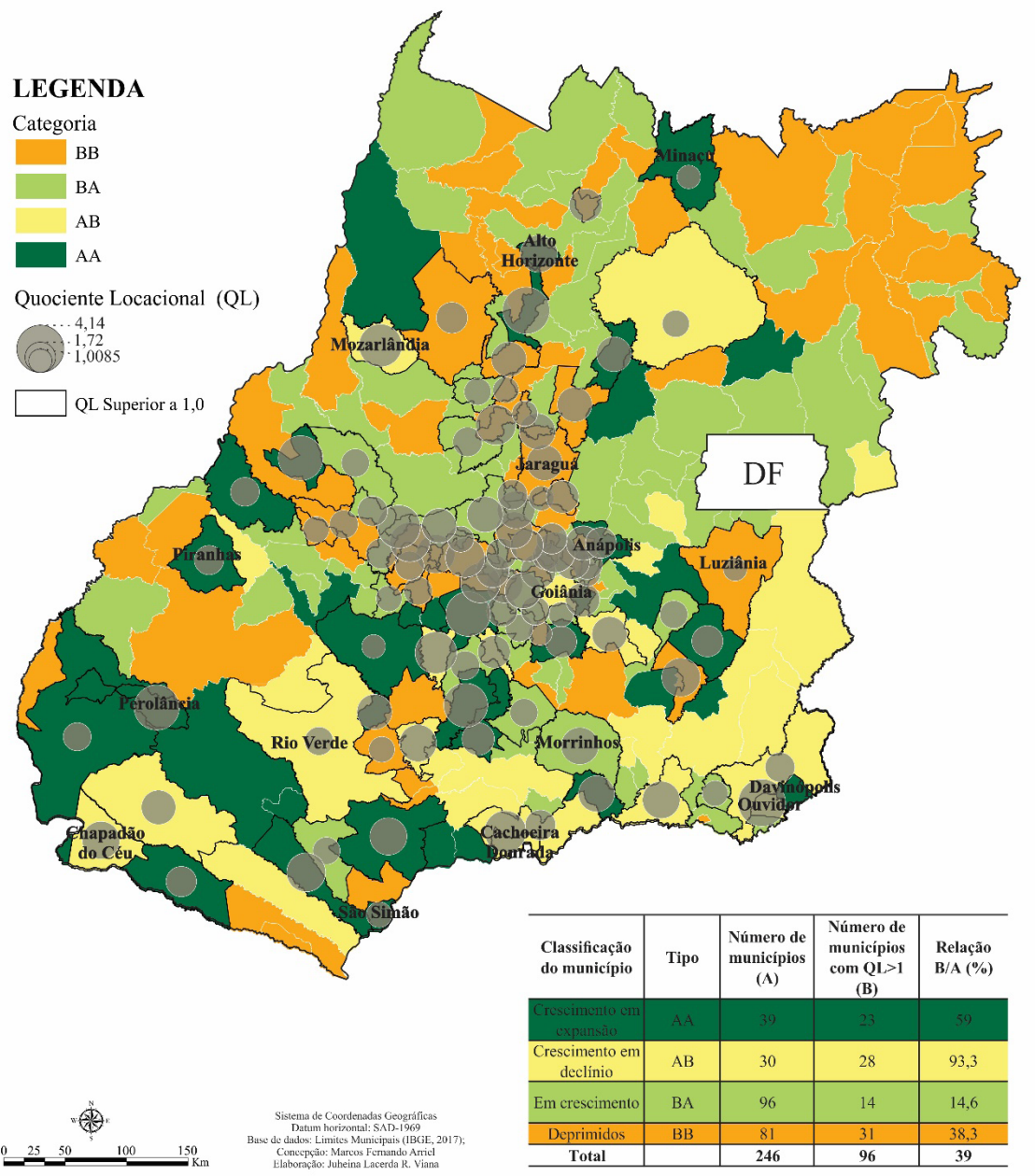

Fonte: Elaboração própria a partir da classificação dos municípios segundo seu padrão de crescimento e o Quociente Locacional (QL). 
Verificou-se que os municípios, cujos padrões de crescimento estão classificados em Crescimento em expansão (AA) e Crescimento em declínio (AB), são aqueles em que a especialização industrial (QL) é mais significativa. Para aqueles municípios classificados como BA e BB, foram encontradas relações baixas, com o nível de especialização industrial.

Dos 39 municípios classificados em AA, 23 são municípios em que há certa especialização industrial (QL>1), ou seja, 59\% dos municípios do padrão AA são de QL superior a 1, podendo indicar relativa importância da atividade industrial para esse conjunto de municípios. A mesma leitura pode ser aplicada aos municípios com padrão de Crescimento em declínio (AB), em que 93,3\% (28) dos 30 municípios possuem certa especialização industrial.

Para esse último conjunto de municípios, é possível fazer a leitura de que, embora a atividade industrial tenha contribuição significativa para que o nível de crescimento (INC) desses municípios esteja acima da média estadual, o comportamento da atividade industrial declinante para boa parte dos segmentos industriais, apontado por Arriel (2017), deve ter afetado o ritmo de crescimento (IRC) deles nos anos mais recentes que antecedem 2015.

\section{Considerações finais}

A atividade industrial exerce papel importante na composição da renda em Goiás, mas perdeu participação em anos recentes, anteriores a 2015. Nesse ano, representava 12,5\% do PIB goiano, mas sua importância já foi maior, 17,1\%, em 2009. Na sua composição, prevalecem segmentos intensivos em recursos naturais, destacando a indústria de alimentos e bebidas e de fabricação de álcool. A crise econômica em anos recentes mudou de forma significativa a estrutura da indústria, com impacto negativo no segmento metalmecânico, sobretudo na montagem de veículos, e na produção de medicamentos, afetadas pela elevação do dólar.

Verificou-se a representatividade do setor industrial na estrutura produtiva de cada um dos municípios, se comparado à economia estadual. Para tanto, utilizou-se do QL, a partir do emprego no referido setor. Constatou-se que, em 150 municípios (61\%), a atividade industrial possui baixa representatividade na estrutura produtiva municipal. Em outros 96 municípios, foram encontrados indícios de que há certa especialização da atividade industrial em suas estruturas produtivas. 
A partir dos dados apurados pelo INC, identificou-se que, dos 246 municípios goianos, 69 (28\%) tiveram seu PIB per capita acima da média estadual em 2015 e, desses, 73,9\% possuíam QL superior a 1, o que possibilita dizer que a presença da indústria teve um papel muito importante no desenvolvimento dos municípios goianos. Quando analisada a dinâmica do crescimento da economia dos municípios goianos no período de 2005 a 2015, calculada pelo IRC, observou-se que a maior parte deles (135 municípios ou 54,9\%) obteve desempenho acima da média estadual, mas apenas 27,4\% apresentaram QL superior a 1. Esse dado indica que a presença da indústria não explica o desempenho superior daqueles municípios, mas ressalta que a crise econômica afetou de forma significativa os municípios industriais.

Na combinação dos indicadores INC e ICR, classificou-se os municípios goianos quanto ao seu padrão de crescimento. Dos 246 municípios, 39 deles (15,9\%) obtiveram padrão AA, sendo o PIB per capita superior à média estadual, e desempenho da sua economia, no período de 2005 a 2015, superior ao registrado pela média do conjunto do estado. Outros 30 municípios $(12,2 \%)$ foram classificados como Crescimento em declínio (AB), 96 (39\%) foram classificados como BA, e 81 municípios $(32,9 \%)$ foram definidos como Deprimidos, quando apresentaram INC e IRC abaixo da média do estado.

De posse dos índices calculados, associou-se o padrão de crescimento dos municípios goianos com aqueles municípios com certa especialização industrial, representada pelo QL. O resultado mostrou que os municípios classificados em Crescimento em expansão (AA) e Crescimento em declínio (AB), são aqueles em que a especialização industrial (QL) é mais significativa, podendo indicar uma importância relativa da atividade industrial para desempenho econômico desse conjunto de municípios.

Assim, considera-se que a atividade industrial, representada pelas indústrias de transformação e extrativa mineral, além de permitir ganhos sucessivos para a expansão da economia goiana, conforme apontado por Arriel (2010, 2017), também tem sido importante para o desempenho econômico de um conjunto expressivo de municípios. A presença de segmentos industriais numa localidade provoca externalidades, que, segundo Marshall (1982), contribui para a o surgimento de outras atividades produtivas e possibilita maior agregação de valor. 


\section{Notas}

1 Este artigo é oriundo de pesquisa financiada pela Funadesp (Fundação Nacional de Desenvolvimento do Ensino SuKior Particular)

2 As commodities minerais ficaram sujeitas à maior instabilidade durante a crise, com alguns dos seus segmentos conseguindo avançar com a queda do dólar e outros não.

\section{Referências}

ARRIEL, M. F. Dinâmica Produtiva e Espacial da Indústria Goiana. 2017. 206 f. Tese (Doutorado) - Instituto de Estudos Socioambientais, Universidade Federal de Goiás, Goiânia, 2017.

ARRIEL, Marcos Fernando. Perfil produtivo e dinâmica espacial da Indústria Goiana (1999-2007). 2010. 102 f. Dissertação (Mestrado em Desenvolvimento e Planejamento Territorial) - Pontifícia Universidade Católica de Goiás, Goiânia, 2010.

BRASIL. Decreto $n^{o}$ 76.900, de 23 de dezembro de 1975. Institui a Relação Anual de Informações Sociais - RAIS e dá outras providências. Brasília, 1975. Disponível em: <http://www.planalto.gov.br/ccivil_03/decreto/antigos/d76900. htm>. Acesso em: nov. 2018.

BRASIL. Ministério do Trabalho e Emprego - MTE. Relação Anual de Informações Sociais - RAIS, 2015. Brasília: disponível em < $\underline{\text { http://pdet.mte.gov. }}$ br/acesso-online-as-bases-de-dados >. Acessado em fev. 2018.

CASTRO, Ana Célia.; FONSECA, Maria da Graça. D. A dinâmica agroindustrial do centro-oeste. Brasília: IPEA, 1995.

CASTRO, Sérgio D.; ARRIEL, Marcos Fernando. Indústria no Brasil Central: Transformações, desafios e oportunidades. Conjuntura Econômica Goiana, Goiânia, n. 36, jul. p. 21-40, 2016. Disponível em: <http://www.imb.go.gov. br/files/docs/publicacoes/conjuntura-economica-goiana/conjuntura36.pdf $>$ Acesso em: 19 maio. 2018.

CASTRO, Sérgio D. Mapeamento das aglomerações produtivas especializadas de Goiás. Identificação e caracterização de APLs potenciais do Estado. Goiânia: SEBRAE-Go, 2004.

DINIZ, Clélio Campolina; CROCCO, Marco Aurélio. Reestruturação econômica e impacto regional: o novo mapa da indústria brasileira. Nova Economia, v.6 n. 1, p. 77-103, 1996.

ESTEVAM, L. A. O tempo da transformação: estrutura e dinâmica da formação econômica de Goiás. Goiânia: Ed. da UCG, 2004.

HADDAD, P. R. (Org.). Economia Regional: teoria e métodos de análise. Fortaleza: BNB/ETENE, 1989. 694 p.

IMB. Instituto Mauro Borges de Estatísticas e Estudos Socioeconômicos. Produto Interno Bruto do Estado de Goiás de 2015. Goiânia: IMB, 2017. 
IMB. Instituto Mauro Borges de Estatísticas e Estudos Socioeconômicos. Banco de Dados Estatísticos. Goiânia: IMB, 2017.

JACOBS, J. (1969). The Economy of Cities. Vintage, New York.

MARSHALL, Alfred. Princípios de economia: tratado introdutório. São Paulo: Abril Cultural, 1982. 2v. (Os economistas)

PIACENTI, C. A. O Potencial de Desenvolvimento Endógeno dos Municípios Paranaenses. 2009. 201f. Tese (Doutorado em Economia Aplicada) - Colegiado de Economia, Universidade Federal de Viçosa, Viçosa, 2009.

SANTOS, M. P.; Souza, E. L.; Barchet, I. Padrões de Crescimento e Aglomerados Industriais nos Municípios do Paraná entre 2000 e 2010. VIII Seminário sobre Desenvolvimento Regional. Santa Cruz do Sul. Universidade de Santa Cruz do Sul, 2017.

Marcos Fernando Arriel - Possui graduação em Economia e mestrado em Desenvolvimento e Planejamento Territorial pela Pontifícia Universidade Católica de Goiás, doutorado em Geografia pela Universidade Federal de Goiás. Atualmente é Gestor Governamental do Estado de Goiás e Superintendente de Micro e Pequenas Empresas, na Secretaria de Desenvolvimento Econômico e Inovação do Estado de Goiás. https://orcid.org/0000-0002-3875-3943

Cintia Neves Godoi - Possui graduação em Geografia pela Universidade Federal de Uberlândia, mestrado em Geografia pela Universidade Federal de Santa Catarina, doutorado em Geografia pela Universidade Federal de Goiás. Atualmente é professora titular do Mestrado Profissional em Desenvolvimento Regional do Centro Universitário Alves. (iD https://orcid.org/0000-0001-5844-4497

Sergio Duarte de Castro - Possui graduação em Economia pela Universidade Católica de Goiás, especialização em Economia pela Universidade Estadual de Campinas e doutorado em Ciência Econômica pela Universidade Estadual de Campinas. É professor titular da Pontifícia Universidade Católica de Goiás. Atualmente realiza estágio pós-doutoral na Universidade de Roma Tre. (D) http://orcid.org/0000-0003-3951-6955

Recebido para publicação em 2 de abril de 2019 Aceito para publicação em 22 de abril de 2019 Publicado em --- de maio de 2019 